\title{
Arbutin production via biotransformation of hydroquinone in in vitro cultures of Aronia melanocarpa (Michx.) Elliott
}

\author{
Inga Kwiecień, Agnieszka Szopa ${ }^{凶}$, Kornelia Madej and Halina Ekiert \\ Department of Pharmaceutical Botany, Jagiellonian University, Collegium Medicum, Kraków, Poland
}

\begin{abstract}
Arbutin (hydroquinone $\beta$-D-glucoside) is a compound of plant origin possessing valuable therapeutic (urinary tract disinfection) and cosmetic (skin whitening) properties, which can be obtained from in vitro cultures of plants belonging to different taxa via biotransformation of exogenously supplemented hydroquinone. Agitating cultures of Aronia melanocarpa were maintained on the Murashige and Skoog medium containing growth regulators: the cytokinin - BAP (6-benzylaminopurine), $2 \mathrm{mg} / \mathrm{l}$ and the auxin NAA ( $a$-naphthaleneacetic acid), $2 \mathrm{mg} / \mathrm{l}$. The biomass was cultured for 2 weeks and then hydroquinone was supplemented at the following doses: $96,144,192,288$ and $384 \mathrm{mg} / \mathrm{l}$ either undivided or divided into two or three portions added at 24-hour intervals. The content of the reaction product - arbutin, was determined using an HPLC method in methanolic extracts from biomass and lyophilized medium samples collected 24 hours after the addition of the last precursor dose. The total amounts of arbutin were very diverse, from 2.71 to $8.27 \mathrm{~g} / 100 \mathrm{~g} \mathrm{~d}$.w. The production of arbutin rose with increasing hydroquinone concentration. The maximum content of the product was observed after hydroquinone addition at $384 \mathrm{mg} / \mathrm{l}$ divided into two portions. Biotransformation efficiency also varied widely, ranging from $37.04 \%$ do $73.80 \%$. The identity of the product arbutin, after its isolation and purification was confirmed by spectral analysis ('H-NMR spectrum). The maximum amount of arbutin obtained was higher than that required by the latest $9^{\text {th }}$ Edition of the Polish Pharmacopoeia and by the newest 8th Edithion of European Pharmacopoeia for Uvae ursi folium $(7.0 \mathrm{~g} / 100 \mathrm{~g} \mathrm{d.w.)}$, and is interesting from practical point of view.
\end{abstract}

Key words: arbutin, black chokeberry, biotransformation, hydroquinone, in vitro cultures

Received: 04 November, 2013; revised: 07 December, 2013;

accepted: 14 December, 2013; available on-line: 30 December, 2013

\section{INTRODUCTION}

Arbutin (hydroquinone O- $\beta$-D-glucoside) is a compound of plant origin that plays an important role in both phytotherapy and cosmetology. Both traditional and modern phytotherapies have long taken advantage of the disinfecting effect on the urinary tract of this compound (Wichtl, 1997; Kohlmünzer, 1998; Stammwitz, 1998; WHO Monographs on selected plants, 2002; Quintus et al., 2005). In traditional Chinese medicine (TCM), arbutin is recommended for treating coughs and bronchitis. The strong antitussive activity of arbutin was confirmed experimentally more than 20 years ago (Strapková et al.,
1991). More recent studies have proven its antifungal and antioxidant activities (Azadbakht et al., 2004).

In cosmetology, arbutin is used mainly for removing skin discolorations. The mechanism of the skin-lightening action consists of the inhibition of tyrosinase, the enzyme catalyzing the conversion of tyrosine via 3,4-dihydroxyphenylalanine (DOPA) and DOPA-quinone to melanin (Akiu et al. 1988; Chang et al., 2003; Rendon \& Gaviria, 2005; Pierzchała \& Jurzak, 2007).

The occurrence of arbutin is characteristic of species of the families Ericaceae, Saxifragaceae and Rosaceae. In European countries, plants of the family Ericaceae, Arctostaphylos wva-ursi (L.) Spreng (bearberry) and Vacinium vitis-idaea $\mathrm{L}$. (red bilberry), are rich source of arbutin (Wichtl, 1997; Kohlmünzer, 1998; WHO Monographs on selected plants, 2002). On the contrary, in Asia, species of the genus Bergenia sp. (bergenia) (Saxifragaceae) (Furmanowa \& Rapczewska 1993; Kohlmünzer, 1998) and Pyrus sp. (pear) (Rosaceae) (Kohlmünzer, 1998; Azadbakht et al., 2004; Cho et al., 2011; Lee et al., 2011) are the best known source of this compound. The natural resources of $A$. uva-ursi and $V$. vitis-idaea in Europe are limited. In most European countries, including Poland, these plants are protected species (Pękoś-Mirkowa \& Mirek, 2003; Recasens et al., 2008). Attempts at artificial, commercial cultivation of these dwarf shrubs, typical of the forest ecosystem (requiring, for example, adequate soil acidity and the presence of mycorrhizal fungi), have not as yet resulted in a complete success (Senderski, 2004). However, trials to acclimatize one of the Asian species - Bergenia crassifolia (L.) Fritsch - in Poland, have been successful (Rumińska, 1991; Senderski, 2004).

Chemical synthesis of arbutin is quite complicated, a three-step process. Biotechnological solutions have long been sought to meet the needs of the pharmaceutical and cosmetic industries (Kurosu et al., 2002; Seo et al., 2012a; 2012b). An overview of biotechnological research directions and an evaluation of their applicability for the production of arbutin was presented by a team from the Department of Pharmaceutical Botany, Jagiellonian University, Collegium Medicum, in Pol. J. Cosmetol. in 2012 (Ekiert et al., 2012). The review presents data, that the greatest success so far has been achieved by using the enzymatic potential of plant cells cultured in vitro for the biotransformation of the exogenously supplied substrate - hydroquinone. The possibility of using microorganisms in this process is limited because the reaction of $\mathrm{O}-\alpha-\mathrm{D}$-glucosylation proceeds better than $\mathrm{O}-\beta$ -

e-mail: a.szopa@uj.edu.p

* Presented at the 5th Central European Congress of Life Sciences "EUROBIOTECH 2013", Kraków, Poland.

Abbreviations: BAP, 6-benzylaminopurine; MS, Murashige and Skoog; NAA, a-naphthaleneacetic acid 


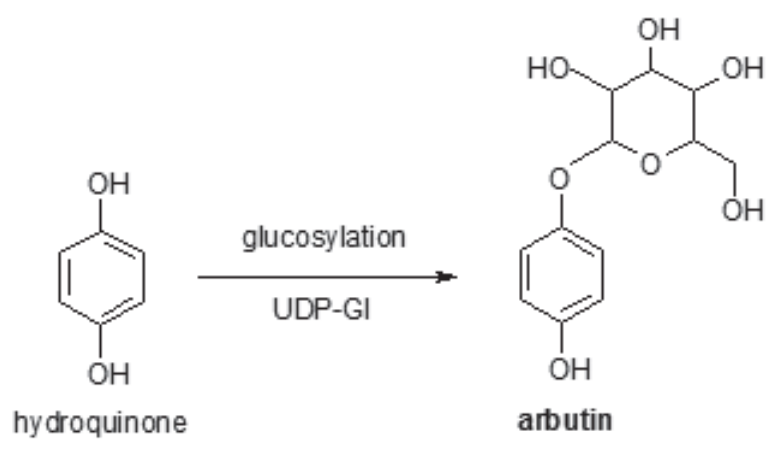

Figure 1. Biotransformation of hydroquinone into arbutin

D-glucosylation in microorganisms. The capacity for the biotransformation of hydroquinone to arbutin has been proven for in vitro cultures of numerous plant species which, under natural conditions, do not produce arbutin, e.g. species of the families Solanaceae (Dušková et al., 1999) and Apocynaceae (Lutterbach \& Stöckigt, 1992). This is because of the prevalence of enzymes from the glucosylases group and the lack of substrate specificity of these enzymes.

In the experiments conducted in our laboratory, we have proven the ability of cells from a variety of other taxa, including Asteraceae, Gentianaceae, Hypericaceae, Lamiaceae, and Rutaceae, also to perform O- $\beta$-Dglucosylation reaction of hydroquinone (Skrzypczak-Pietraszek et al., 2005; Piekoszewska et al., 2010).

Aronia melanocarpa (Rosaceae) is a medicinal, cosmetic and culinary plant species, native to North America and cultivated in Europe and Asia. The fruits of this species are a rich source of different groups of metabolites, e.g. flavonoids, anthocyanins, phenolic acids, tannins, pectins, vitamin C and bioelements (Zdunczyka et al., 2002; Oszmański \& Wojdyło, 2005; Silmestad et al., 2005; Kulling \& Rawel, 2008; Kokotkiewicz et al., 2010).

In vitro cultures of $A$. melanocarpa have not yet been the object of biotechnological research focused on the production of secondary metabolites. Few papers have only dealt with the development of micropropagation protocols for this species (Litwińczuk, 2002; 2013).

In our laboratory in vitro cultures of $A$. melanocarpa, with varying degrees of differentiation - shoot and callus cultures - have demonstrated the ability to produce phenolic acids (Szopa \& Ekiert, 2013; Szopa et al., 2013). In shoot cultures, the resulting amounts of selected compounds about $50-90 \mathrm{mg} / 100 \mathrm{~g}$ d.w. have proven the applicability of the method. These results encouraged us to investigate the potential for O- $\beta$-D-glucosylation of hydroquinone to arbutin (Fig. 1). The main groups of metabolites, the presence of which in $A$. melanocarpa has been confirmed (flavonoids, anthocyanins), are present in the form of glycoside conjugates. One could therefore suppose that $A$. melanocarpa cells cultured in vitro would also have a considerable enzymatic potential for carrying out the glucosylation reaction.

The initial experiments demonstrated the capacity of cells from shoot cultures maintained on MS medium containing $2 \mathrm{mg} / \mathrm{l}$ benzylaminopurine (BAP) and $2 \mathrm{mg} / \mathrm{l}$ naphthaleneacetic acid (NAA) for converting exogenously supplied hydroquinone into arbutin (Kwiecień et al., 2013). The selection of shoot cultures with a high degree of differentiation, as opposed to callus cultures, helped to avoid the often-described adverse effects of hydroquinone on the appearance, growth and production capacity of the biomass.
The aim of the present study was to examine the reproducibility of the preliminary results of process optimization. The optimization consisted of testing various dosages of the precursor (hydroquinone 100-400 mg/l), and various methods of its administration (a single dose, divided into two or three portions).

Similar experiments performed earlier in our laboratory with in vitro cultures of Ruta graveolens, Ruta graveolens ssp. divaricata and Hypericum perforatum have proven that those studies were fully justified. As a result of the optimization, a 2.6- to 6.0-fold increase in the amount of the product (arbutin) was obtained (Zubek et al., 2009; Piekoszewska et al., 2010).

\section{MATERIALS AND METHODS}

Establishment of in vitro cultures. The in vitro cultures of $A$. melanocarpa were established from leaf buds of the plants from the Rogów Arboretum, Warsaw University of Life Sciences, Forest Experimental Station in Rogów (Poland) (Szopa et al., 2013). The resulting shoot culture was cultivated on MS (Murashige \& Skoog, 1962) medium supplemented with $2 \mathrm{mg} / 1$ cytokinin BAP (6-benzylaminopurine), and $2 \mathrm{mg} / 1$ auxin - NAA $(\alpha$-naphthaleneacetic acid) $(\mathrm{pH}=5.7)$. The cultures were grown under constant $(24 / 24 \mathrm{~h})$ artificial light $(16 \mu \mathrm{mol}$. $\mathrm{m}^{-2} \cdot \mathrm{s}^{-1}$, LF-40 W lamp, daylight, Piła), at $25 \pm 2^{\circ} \mathrm{C}$.

Experimental in vitro cultures. Agitating shoot cultures were maintained in Erlenmayer flasks $(500 \mathrm{ml})$ containing $100 \mathrm{ml}$ of medium in which the inoculum was $4 \mathrm{~g}$ of fresh biomass in each, on MS medium supplemented with BAP $(2 \mathrm{mg} / \mathrm{l})$ and NAA $(2 \mathrm{mg} / \mathrm{l})(\mathrm{pH}$ $=5.7)$ at the same light and temperature conditions as the initial cultures. The culture flasks were maintained on a rotary shaker (Altel) at $140 \mathrm{rpm}$ (vibrations amplitude $35 \mathrm{~mm})$.

Biotransformation experiment. Fourteen days after inoculation a substrate (hydroquinone, Merck-Darmstadt, Germany) dissolved in water (concentration 1 or $2 \mathrm{mg} / \mathrm{ml}$ ) was administered aseptically through a membrane filter (Millex, Millipore, $0.22 \mu \mathrm{m}$ ) into the culture flasks. Additionally $100 \mathrm{ml}$ of fresh medium was added to each flask. The final concentration of hydroquinone were: 96, 144, 192, 288, and $384 \mathrm{mg} / \mathrm{l}$ of medium (method developed by Skrzypczak-Pietraszek, unpublished). The hydroquinone was added in single dose or doses divided into two or three portions administered at 24-h intervals. The biomass and culture media were harvested separately $24 \mathrm{~h}$ after the addition of the last dose of the precursor. The biomass was dried and the media lyophilized. The experiment was carried out in three independent replications.

Extraction. One-gram of dried biomass was milled and extracted twice with boiling methanol $(2 \times 50 \mathrm{ml})$ for $4 \mathrm{~h}(2 \times 2 \mathrm{~h})$. The methanol was evaporated to dryness and the remains were dissolved in methanol (HPLC grade). The lyophilized media were dissolved in methanol, too.

HPLC analysis. Methanol extracts were analyzed by the HPLC method (Štambergová et al., 1985). Separation was performed using HPLC-system (Merck) and Purospher RP-18e analytical column $(4 \times 250 \mathrm{~mm}, 5 \mu \mathrm{m})$ with mobile phase consisting of methanol/water $(1: 9, \mathrm{v} / \mathrm{v})$. The flow rate was $1 \mathrm{ml} / \mathrm{min}$. Arbutin and hydroquinone were detected at $285 \mathrm{~nm}$ using DAD detector (retention times: 3.7 and $5.5 \mathrm{~min}$, respectively). Qualification and quantification analysis were made by comparison with reference standards, respectively. The amounts of these 
A

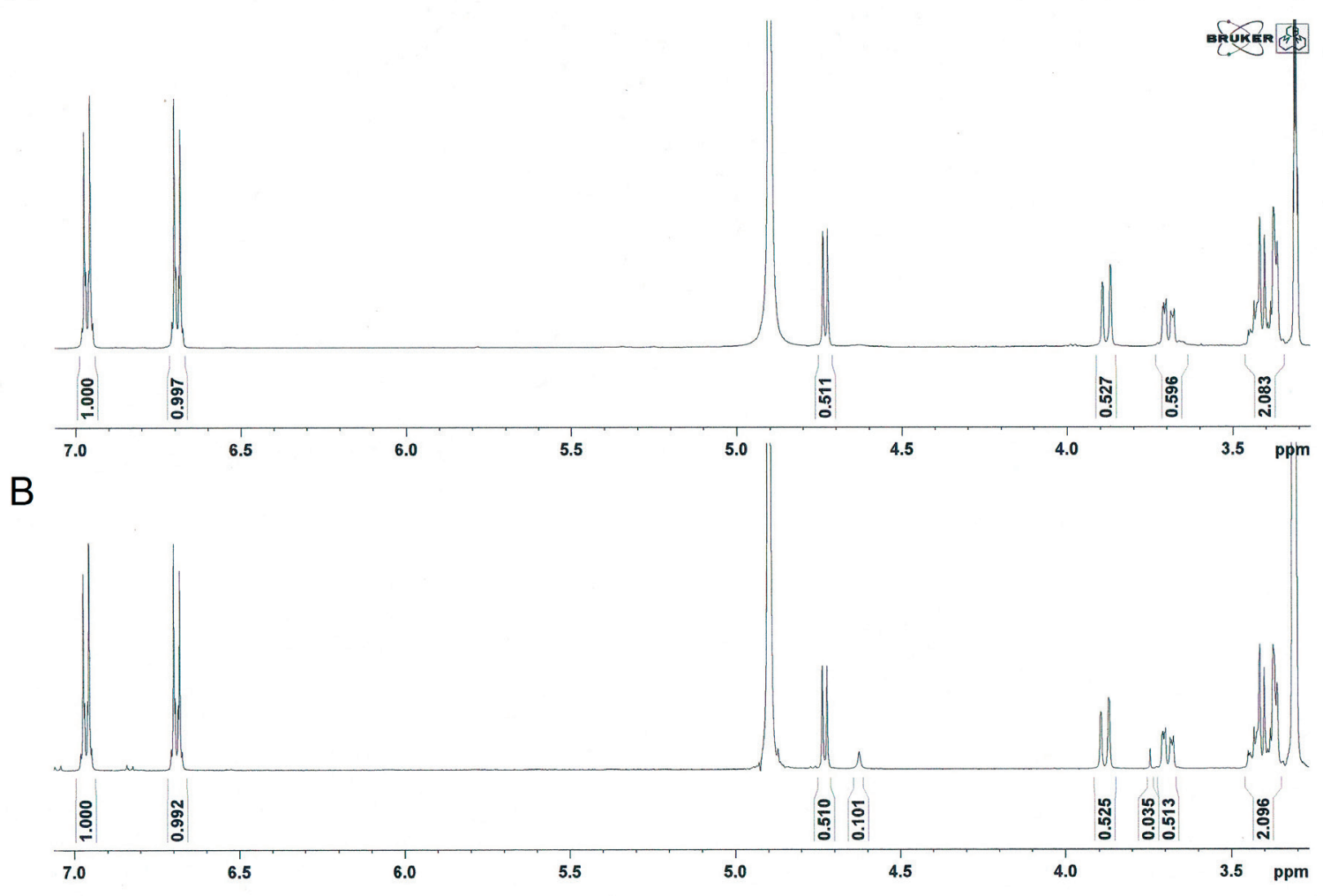

Figure 2. Comparison of 1H-NMR spectra of the sample tested (384 mg/l, 3 portions of precursor) (A) and the arbutin standard (B)

compounds were calculated from calibration curves, putting in relation the mean peak areas with standard concentrations.

Calculation of biotransformation efficiency. The efficiency of the biotransformation of hydroquinone into arbutin was calculated using the following formula:

efficiency $=\mathrm{a} / \mathrm{b} \times 100 \%$

a - total amount of arbutin produced per Erlenmayer flask (in the biomass and $250 \mathrm{ml}$ of medium); b - maximum amount of arbutin obtained theoretically from a given amount of hydroquinone

Isolation and identification of arbutin. Methanolic extract was chromatographed on TLC plates (Merck, no 1.05553.0001) with ethyl acetate : formic acid : water (88:6:6, v/v/v) solvent system. Fractions containing arbutin were eluted with methanol and analyzed by TLC with $\mathrm{n}$-hexane : ethyl acetate : methanol $(2: 1: 2, \mathrm{v} / \mathrm{v} / \mathrm{v})$ as mobile phase. ${ }^{1} \mathrm{H}-\mathrm{NMR}$ spectrum was prepared (AVANCE III Bruker $500 \mathrm{MHz}, \mathrm{CD}_{3} \mathrm{OD}$ ).

Statistical analysis. The obtained results are expressed as mean \pm S.D. of three independent determinations. Statistical significance of differences was evaluated using a two-way ANOVA followed by an Least Significant Difference test for post-hoc comparisons. The differences were statistically significant when $p<0.05$. The analyses were conducted using Statistica ver.10.

\section{RESULTS}

The biotransformation product (arbutin) was identified. The identity of this compound isolated from methanolic extracts of biomass from in vitro cultures was confirmed by comparing its parameters using TLC
(Rf), HPLC (Rt, UV spectrum) and ${ }^{1} \mathrm{H}-\mathrm{NMR}$ spectrum. The NMR spectra of the tested sample and the arbutin standard showed the presence of the same resonance signals (Fig. 2).

High doses of hydroquinone usually produce adverse effects on the morphological features, growth and biosynthetic capacities of biomass cultured in vitro. The present experiment did not show any negative effect of higher dosages of hydroquinone (over $100 \mathrm{mg}$ ) on biomass appearance. However, a slight inhibition of biomass growth both when the precursor was added as a single dose and when the doses were divided into 2 or 3 portions was recorded. Based on previous experiments, cultures with a higher degree of organogenesis (shoot culture) were used. That was a guarantee of their lower vulnerability to exogenously applied hydroquinone.

The arbutin was accumulated mostly in biomass cultured in vitro. At low hydroquinone concentrations, arbutin levels in culture media were low (6.6-13.7\%), while, at higher dosages of $300-400 \mathrm{mg} / \mathrm{l}$, the content of the product in media amounting to $30 \%$ (Table 1 ). The total contents of the product (in biomass and medium) varied significantly depending on the precursor concentration added to culture (from 27.1 to $82.7 \mathrm{mg} / \mathrm{g} \mathrm{d} . w$. .).

Arbutin content in the cultured biomass ranged from 24.79 to $58.92 \mathrm{mg} / \mathrm{g} \mathrm{d}$.w., while its level in culture medium varied from 10.56 to $150.32 \mathrm{mg} / 1$ (Table 1$)$. When a single dose of hydroquinone was elevated from 100 $\mathrm{mg} / \mathrm{l}$ to $400 \mathrm{mg} / \mathrm{l}$, the inhibition of biomass growth deepened; however, arbutin content in the cultured biomass and in media rose from 26.22 to $56.83 \mathrm{mg} / \mathrm{g} \mathrm{d}$.w. and from 10.56 to $101.44 \mathrm{mg} / \mathrm{l}$, respectively (Table 1 ).

When higher dosages of hydroquinone were divided into 2 or 3 portions, biomass growth in vitro was less inhibited and the total content of the product (in the bio- 
Table 1. Amounts of arbutin and the efficiency of the biotransformation process in in vitro shoot cultures of Aronia melanocarpa grown on MS medium (BAP $-2 \mathrm{mg} / \mathrm{l}$ and NAA $-2 \mathrm{mg} / \mathrm{l}$ )

\begin{tabular}{|c|c|c|c|c|c|c|c|}
\hline \multirow{2}{*}{$\begin{array}{l}\text { Concentration of } \\
\text { precursor (mg/l) }\end{array}$} & \multirow{2}{*}{$\begin{array}{l}\text { Method of pre- } \\
\text { cursor supply }\end{array}$} & \multirow{2}{*}{$\begin{array}{l}\text { Arbutin content } \\
\mathrm{mg} / \mathrm{g} \text { d.w. } \pm \text { S.D. }\end{array}$} & \multicolumn{2}{|c|}{$\begin{array}{l}\text { Arbutin content } \\
\text { in biomass }\end{array}$} & \multicolumn{2}{|c|}{$\begin{array}{l}\text { Arbutin content } \\
\text { in medium }\end{array}$} & \multirow{2}{*}{$\begin{array}{l}\text { Biotransformation effi- } \\
\text { ciency }(\%) \pm \text { S.D. }\end{array}$} \\
\hline & & & mg/g d.w. & $\%$ & $\mathrm{mg} / \mathrm{l}$ & $\%$ & \\
\hline \multirow{3}{*}{96} & single dose & $28.1 \pm 1.23$ deghijkImno & 26.22 & 93.36 & 10.56 & 6.64 & $67.01 \pm 4.8 \mathrm{jmno}$ \\
\hline & 2 portions & $29.1 \pm 0.48$ deghijklmno & 25.76 & 88.72 & 19.08 & 11.28 & $71.34 \pm 4.9 \mathrm{jm} \mathrm{no}$ \\
\hline & 3 portions & $27.1 \pm 5.62$ deghijklmno & 24.79 & 91.68 & 14.56 & 8.32 & $73.80 \pm 9.3 \mathrm{gjkm} \mathrm{o}$ \\
\hline \multirow{3}{*}{144} & single dose & $43.4 \pm 0.65$ abcgik Imno & 38.39 & 88.67 & 29.16 & 11.33 & $72.31 \pm 11.8 \mathrm{jkmno}$ \\
\hline & 2 portions & $39.1 \pm 4.82$ abcghiklmno & 35.84 & 91.75 & 21.28 & 8.25 & $72.45 \pm 3.1 \mathrm{jkm} \mathrm{no}$ \\
\hline & 3 portions & $36.3 \pm 4.81 \mathrm{ghijk} / \mathrm{mno}$ & 33.89 & 93.42 & 17.24 & 6.58 & $73.68 \pm 2.4 \mathrm{jkm} \mathrm{no}$ \\
\hline \multirow{3}{*}{192} & single dose & $53.1 \pm 7.64$ abcdefk $I m n o$ & 45.77 & 86.30 & 39.12 & 13.70 & $60.18 \pm 8.7 \mathrm{~cm}$ \\
\hline & 2 portions & $52.5 \pm 5.56$ abcefk Imno & 45.42 & 86.49 & 44.48 & 13.51 & $69.36 \pm 6.6^{\mathrm{j} \mathrm{m} \mathrm{no}}$ \\
\hline & 3 portions & $48.5 \pm 5.23$ abcfjklmno & 43.13 & 89.02 & 38.24 & 10.98 & $73.33 \pm 4.7^{\mathrm{jkm} \mathrm{no}}$ \\
\hline \multirow{3}{*}{288} & single dose & $60.5 \pm 6.34$ abcdefikmno & 42.09 & 69.64 & 101.44 & 30.36 & $46.94 \pm 6.3$ abcdefhil \\
\hline & 2 portions & $75.8 \pm 0.40 a b c d e f g h i j$ & 53.24 & 70.99 & 119.44 & 29.01 & $57.83 \pm 11.3 a b c d e f i m$ \\
\hline & 3 portions & $69.4 \pm 1.89 a b c d e f g h i m n$ & 51.45 & 74.46 & 111.4 & 25.54 & $61.28 \pm 8.6 \mathrm{mo}$ \\
\hline \multirow{3}{*}{384} & single dose & $79.4 \pm 13.89 a b c d e f g h i j l$ & 56.83 & 72.09 & 98.12 & 27.91 & $37.04 \pm 3.8 a b c d e f g h i k \operatorname{lno}$ \\
\hline & 2 portions & $82.7 \pm 7.54$ abcdefghijl & 57.48 & 69.96 & 150.32 & 30.04 & $52.71 \pm 11.2$ abcdefhim \\
\hline & 3 portions & $77.6 \pm 1.08 a b c d e f g h i j$ & 58.92 & 76.92 & 114.96 & 23.08 & $52.48 \pm 13.4$ abcdefhim \\
\hline
\end{tabular}

Statistically significant differences $p<0.05: \mathrm{a}-$ vs. 96(1); b - vs. 96(2); c - vs. 96(3); d - vs. 144(1); e - vs. 144(2); f - vs. 144(3); g - vs. 192(1); h vs. 192(2); i - vs. 192(3); j - vs. 288(1); $\mathrm{k}$ - vs. 288(2); I-vs. 288(3); $\mathrm{m}-$ vs. 384(1); $\mathrm{n}-$ vs. 384(2); o-vs. 384(3).

mass and in the medium) distinctly rose from 29.1 to 82.7 $\mathrm{mg} / \mathrm{g}$ d.w. at 2 portions and from 27.1 to $77.6 \mathrm{mg} / \mathrm{g}$ d.w. at 3 portions (Table 1). When the precursor dose was divided into 2 portions, arbutin content in cultured biomass fluctuated in a wide range from 25.76 to $57.48 \mathrm{mg} / \mathrm{g}$ d.w. The content of the product in culture medium also rose from 19.08 to $150.32 \mathrm{mg} / \mathrm{l}$ (Table 1). However, when the dose of the precursor was divided into 3 portions, arbutin levels were also very varied (from 24.79 to $58.92 \mathrm{mg} / \mathrm{g}$ d.w.), which was accompanied by a significant increase in the content of the product in culture medium (from 14.56 to $114.96 \mathrm{mg} / \mathrm{l}$ ) (Table 1).

Statistically significant differences $(p<0.05)$ in arbutin content were found between hydroquinone concentration, and in two-way interactions between hydroquinone concentrations/hydroquinone supply.

The efficiency of hydroquinone biotransformation into arbutin varied from $37.0 \%$ to $73.8 \%$. At low precursor dosages of 100-200 mg, biotransformation efficiency was similar regardless of the manner of precursor administration (67.0-73.8\%). At higher hydroquinone concentrations, precursor addition in one portion decrease the efficiency of biotransformation from 60.18 to $37.04 \%$. With precursor addition in 2 or 3 portions a lower decrease was observed in biotransformation efficiency from 69.36 to $52.71 \%$ ( 2 portions) and from 73.33 to $52.48 \%$ ( 3 portions), in comparison with the efficiency of one dose of precursor (Table 1).

In the case of reaction efficiency statistically significant differences $(p<0.05)$ between hydroquinone concentrations and hydroquinone supply were found.

\section{DISCUSSION}

The damaging effect of high dosages of hydroquinone (over $100 \mathrm{mg} / \mathrm{l}$ ) on plant cells cultured in vitro is a well- known phenomenon (Suzuki et al., 1987; Yokoyama \& Inomata, 1998). However, A. melanocarpa shoots cultured in the present study, i.e. the culture of a high degree of differentiation, proved to be resistant to the harmful effect of hydroquinone. We observed only a slight decrease in biomass growth. Similarly, in previous experiments with highly differentiated shoot cultures (R. graveolens and $H$. perforatum) and shoot-differentiating callus cultures R. graveolens ssp. divaricata) higher hydroquinone dosages also did not suppress biomass growth (Skrzypczak-Pietraszek et al., 2005; Piekoszewska et al., 2010).

A. melanocarpa cultures were maintained on MS medium supplemented with $2 \mathrm{mg} / \mathrm{l} \mathrm{BAP}$ and $2 \mathrm{mg} / 1 \mathrm{NAA}$. The choice of the medium with the basal composition according to Murashige-Skoog and the above contents of growth regulators, was based on our earlier experiments on phenolic acid accumulation in these cultures. In these experiments, many variants of Murashige-Skoog (Szopa \& Ekiert, 2013) and Linsmaier-Skoog (Szopa et al., 2013) medium differing in BAP and NAA contents were tested. MS medium supplemented with $2 \mathrm{mg} / 1$ BAP and $2 \mathrm{mg} / 1 \mathrm{NAA}$ was chosen as the best growth medium and a good productive medium.

Optimization of the biotransformation process allowed us to obtain a 2.4-fold increase in product content in biomass. In cultures of three other species maintained in our laboratory, i.e. H. perforatum, R. graveolens and $R$. graveolens ssp. divaricata, optimization led to a 4.3-, 4.9and 2.6-fold rise in arbutin content in biomass, respectively (Piekoszewska et al., 2010; Zubek et al., 2009).

The maximum arbutin content in our $A$. melanocarpa in vitro culture (the sum of the product content in biomass and medium) was $8.27 \mathrm{~g} / 100 \mathrm{~g}$ d.w., while the maximum arbutin levels in biomass from in vitro cultures of H. perforatum, R. graveolens and R. graveolens ssp. divaricata amounted to 5.6, 7.8 and $8.3 \mathrm{~g} / 100 \mathrm{~g}$ d.w., respectively (Piekoszewska et al., 2010; Zubek et al., 2009). However, 
it should be noted (by proceeding with caution) that cultures of those three species were maintained on medium supplemented with identical contents of growth regulators but the basal composition of medium was different; namely, it was the medium according to LinsmaierSkoog (1965). The obtained total content of arbutin in A. melanocarpa in vitro cultures was almost identical to that obtained in R. graveolens ssp. divaricata cultures.

The maximum efficiency of hydroquinone biotransformation into arbutin equaling $73.8 \%$ was higher than the maximum efficiency of this process in cultures of $H$. perforatum (63.1\%) and R. graveolens (66.4\%) (Piekoszewska et al., 2010).

Although the maximum content of arbutin obtained by us is high, it is much lower than the contents obtained in other research centers using, for instance, a continuous hydroquinone supplementation in in vitro cultures of Rawwolfia serpentina - $23.7 \mathrm{~g} \%$ (Lutterbach \& Stöckigt, 1992), Catharanthus roseus - $45.0 \mathrm{~g} \%$ (Yokoyama \& Inomata, 1998) and Datura innoxia - $50.0 \mathrm{~g} \%$ (Suzuki et al., 1987). Nevertheless, the total content of arbutin obtained through the optimization process of hydroquinone biotransformation, i.e. $8.27 \mathrm{~g} / 100 \mathrm{~g}$ d.w., is higher than the content required for a plant raw material; bearberry leaf (Uvae ursi folium) according to the Polish Pharmacopoeia (9 th $^{\text {th }}$ edn.) $-7.0 \%$ (Polish Pharmacopoeia, 2011) and the newest $8^{\text {th }}$ edn. of the European Pharmacopoeia - 7.0\% (European Pharmacopoeia, 2013). Hence, the obtained results are interesting from a practical perspective.

The present studies have proved the high biochemical potential of $A$. melanocarpa cells. In in vitro cultures, these cells produced not only considerable amounts of some phenolic acids - like salicylic acid, p-hydroxybenzoic acid, p-coumaric acid but they also showed the capacity for hydroquinone $\mathrm{O}-\beta-\mathrm{D}$-glucosylation into arbutin. A. melanocarpa cultures can be used as an excellent research model for further biotechnological studies into its potential practical application aiming to obtain important products possessing therapeutic and/or cosmetic values.

\section{REFERENCES}

Akiu S, Suzuki Y, Fujinuma Y, Asahara T, Fukuda M (1988) Inhibitory effect of arbutin on melanogenesis: biochemical study in cultured B16 melanoma cells and effect on the UV-induced pigmentation in human skin. Proc Jpn Soc Invest Deramtol 12: 138-139.

Azadbakht M, Marston A, Hostettmann K, Ramezani M, Jahromi Maghddam M (2004) Biological activity of leaf extract and phenol glycoside arbutin of Pyrus boisseriana Buhse. J Med Plants 3: 9-14.

Chang M-L, Chang Ch-M (2003) Simultaneous HPLC determination of hydrophylic whitening agents in cosmetic products. I Pharm Biomed Anal 33: 617-626.

Cho J-Y, Park KY, Lee HJ, Lee SH, Cho JA, Kim W-S, Shin SC, Park $\mathrm{KH}$, Moon JH (2011) Recovery of arbutin in high purity from fruit peels of pear (Pyrus pyrifolia Nakai). Food Sci Biotechnol 20: 801-807.

Dušková J, Dušek J, Jahodár L (1999) Zur Biotransformation von Hydrochinon zu Arbutin in den In Vitro-Kulturen. Herba Pol 45: 23-26.

Ekiert H, Kwiecień I, Szopa A, Muszyńska B (2012) Possibilities of arbutin production using plant biotechnology methods. Pol J Cosmetol 15: 151-162.

European Pharmacopoeia $8^{\text {th }}$ Edition (2013) Bearberry leaf (Uvae ursi folium), European Directorate for the Quality of Medicines, Council of Europe, vol. 1, pp 1162-1163. Strasbourg, France.

Furmanowa M, Rapczewska L (1993) Bergenia crassifolia (L.) Fritsch (Bergenia): Micropropagation and arbutin contents. In Biotechnology in Agriculture and Forestry. Vol. 21 Medicinal and Aromatic Plants IV. Bajaj YPS ed, pp 18-33, Springer Verlag, Berlin, Heidelberg.

Kohlmünzer S (1998) Pharmacognosy. Wydawnictwo Lekarskie PZWL, pp 233-237, Warszawa, Poland (in Polish)

Kokotkiewicz A, Jaremicz Z, Luczkiewicz M (2010) Aronia plants: a review of traditional use, biological activities, and perspectives for modern medicine. J Med Food 13: 255-269.
Kulling SE, Rawel HM (2008) Chokeberry (Aronia melanocarpa) - A review on the characteristic components and potential health effects. Planta Med 74: 1625-1634.

Kurosu J, Sato T, Yoshida K, Tsugane T, Shimura S, Kirimura K, Kino K, Usami S (2002) Enzymatic synthesis of $\alpha$-arbutin by $\alpha$-anomer-selective glucosylation of hydroquinone using lyophilized cells of Xanthomonas campestris WU-9701. I Biosi Bioeng 93: 328-330.

Kwiecień I, Majcher J, Ekiert H (2013) Biotransformation of hydroquinone into arbutin in in vitro cultures of Aronia melanocarpa - preliminary results. 7th Polish-German Symposium on Pharmaceutical Sciences, Gdańsk, Abstracts pp 136.

Lee KH, Cho J-Y, Lee HJ, Park KY, Ma Y-K, Lee S-H, Cho JA, Kim WS, Park KH, Moon J-H (2011) Isolation and identification of phenolic compounds from Asian pear Pyrus pyrifolia Nakai fruit peel. Food Sci Biotechnol 20: 1539-1545.

Linsmaier EM, Skoog F(1965) Organic growth factor requirements of tobacco tissue cultures. Physiol Plant 18: 100-127.

Litwińczuk W (2002) Propagation of black chokeberry (Aronia melanocarpa Elliot) through in vitro culture. Electron J Pol Agricult University Horticult 5: 1-8.

Litwińczuk W (2013) Micropropagation of chokeberry by in vitro axillary shoot proliferation. Methods Mol Biol 11013: 179-186.

Lutterbach R, Stöckigt J (1992) High yield formation of arbutin from hydroquinone by cell-suspension cultures of Rawvolfia serpentina. Helv Chim Acta 75: 2009-2011.

Murashige T, Skoog F (1962) A revised medium for rapid growth and bioassays with tobacco tissue cultures. Physiol Plant 15: 473-497.

Oszmański J, Wojdyło A (2005) Aronia melanocarpa phenolics and their antioxidant activity. Eur Food Res Technol 221: 809-813.

Pękoś-Mirkowa H, Mirek Z (2003) Flora of Poland. Atlas of protected plants. Multico Oficyna Wydawnicza, pp 132-133, Warszawa, Poland (in Polish).

Piekoszewska A, Ekiert H, Zubek S (2010) Arbutin production in Ruta graveolens L. and Hypericum perforatum L. in vitro cultures. Acta Physiol Plant 32: 223-229.

Pierzchała E, Jurzak M (2007) Active substances in cosmetic products inhibiting synthesis of melanin. Dermatol Estet 9: 381-383 (in Polish).

Polish Pharmacopoeia 9th Edition (2011) Uvae ursi folium. The Office for Registration of Medicinal Products, Medical Devices and Biocidal Products, vol. 1, pp 1410-1411. Warszawa, Poland.

Quintus J, Kovar KA, Link P, Hamacher H (2005) Urinary excretion of arbutin metabolites after oral administration of bearberry leaf extracts. Planta Med 71: 147-152.

Recasens J, Ninot P, Cristobal R, Ayemerich P (2008) Sustinable wild harvesting of Arctostaphylos wva-ursi in the Pyrenees as a conservation practice. I Herbs Spices Med Plants 14: 1-12.

Rendon M, Gaviria J (2005) Review of skin-lightening agents. Dermatol Surg 31: 886-889.

Rumińska A (1991) Herb grower's guide. Państwowe Wydawnictwo Rolnicze i Leśne, Poznań, Poland (in Polish).

Senderski ME (2004) Almost everything about herbs. Senderski ME ed, Podkowa Leśna, Poland (in Polish).

Seo D-H, Jung J-H, Ha S-J, Cho H-K, Jung D-H, Kim T-J, Baek N-I, Yoo S-H, Park C-S (2012a) High-yield enzymatic bioconversion of hydroquinone to $\alpha$-arbutin, a powerful skin lightening agent, by amylosucrase. Appl Microbiol Biotechnol 94: 1189-1197.

Seo D-H, Jung J-H, Lee J-h, Jeon E-J, Kim W, Park C-S (2012b) Biotechnological production of arbutins ( $\alpha$ - and $\beta$-arbutins), skinlightening agents, and their derivatives. Appl Microbiol Biotechnol 95: 1417-1425.

Silmestad R, Torskangerpoll K, Nateland HS, Johannessen T, Giske NH (2005) Flavonoids from black chokeberries, Aronia melanocarpa. J Food Compos Anal 18: 61-68.

Skrzypczak-Pietraszek E, Szewczyk A, Piekoszewska A, Ekiert H (2005) Biotransformation of hydroquinone to arbutin in plant in vitro cultures - preliminary results. Acta Physiol Plant 27: 79-87.

Štambergová A, Supčiková M, Leifertová I (1985) Evaluation of phenolic substances in Arctostaphylos uvae-ursi. IV. Determination of arbutin, methylarbutin and hydroquinone in the leaves by HPLC. Ceskoslov Farm 34: 179-182 (in Czech).

Stammwitz U (1998) Pflanziche Harnwegsdesinifizenzien zien - heute noch aktuell? Zeitsch Phytother 19: 90-95.

Strapková A, Jahodár L, Nosalová G (1991) Antitussive effect of arbutin. Pharmazie 46: 611-612.

Suzuki T, Yoshioka T, Tabata M, Fujita Y (1987) Potential of Datura innoxia cell suspension cultures for glucosylating hydroquinone. Plant Cell Rep 6: 275-278.

Szopa A, Ekiert H (2013) Production of biologically active phenolic acids in Aronia melanocarpa (Michx.) Elliott in vitro cultures cultivated on different variants of the Murashige and Skoog medium. Plant Growth Regul DOI 10.1007/s10725-013-9835-2.

Szopa A, Ekiert H, Muszyńska B (2013) Accumulation of hydroxybenzoic acids and other biologically active phenolic acids in shoot and callus cultures of Aronia melanocarpa (Michx.) Elliott (black chokeberry). Plant Cell Tiss Org Cult 113: 323-329. 
WHO Monographs on selected plants (2002) Folium Uvae ursi, World Health Organization, Vol. 2, pp 342-351, Geneva, Switzerland.

Wichtl M (1997) Teedrogen und Phytopharmaka. Wissenschaftlische Verlagsgesellschaft mbH, pp 599-602, Stuttgart, Germany.

Yokoyama M, Inomata S (1998) Catharanthus roseus (Periwinckle): In vitro culture and high-level production of arbutin by biotransformation. In Biotechnology in Agriculture and Forestry. Vol. 41 Medicinal and Aromatic Plants X. Bajaj YPS ed, pp 67-80. Springer, Berlin, Heidelberg, New York.
Zdunczyka Z, Frejnagela S, Wróblewska M, Juśkiewicz J, Oszmiański J, Estrellac I (2002) Biological activity of polyphenol extracts from different plant sources. Food Res Intern 35: 183-186.

Zubek S, Janas E, Ekiert H (2009) Optimisation of hydroquinone biotransformation conditions in in vitro cultures of Ruta graveolens ssp. divaricata. XXXVIII Zjazd Polskich Ogrodów Botanicznych. Poznań 2009, Abstracts pp 99 (in Polish). 